ARTICLE

https://doi.org/10.1038/s41467-019-11608-9

OPEN

\title{
Bacteria evoke alarm behaviour in zebrafish
}

\author{
Joanne Shu Ming Chia (ib ${ }^{1}$, Elena S. Wall ${ }^{2}$, Caroline Lei Wee (i) ${ }^{3}$, Thomas A.J. Rowland (i) ${ }^{1,5}$, Ruey-Kuang Cheng ${ }^{1}$, \\ Kathleen Cheow (1) ${ }^{1}$, Karen Guillemin (10) ${ }^{2,4}$ \& Suresh Jesuthasan ${ }^{1,3}$
}

When injured, fish release an alarm substance (Schreckstoff) that elicits fear in members of their shoal. Although Schreckstoff has been proposed to be produced by club cells in the skin, several observations indicate that these giant cells function primarily in immunity. Previous data indicate that the alarm substance can be isolated from mucus. Here we show that mucus, as well as bacteria, are transported from the external surface into club cells, by cytoplasmic transfer or invasion of cells, including neutrophils. The presence of bacteria inside club cells raises the possibility that the alarm substance may contain a bacterial component. Indeed, lysate from a zebrafish Staphylococcus isolate is sufficient to elicit alarm behaviour, acting in concert with a substance from fish. These results suggest that Schreckstoff, which allows one individual to unwittingly change the emotional state of the surrounding population, derives from two kingdoms and is associated with processes that protect the host from bacteria.

\footnotetext{
${ }^{1}$ Lee Kong Chian School of Medicine, Nanyang Technological University, Singapore, Singapore. ${ }^{2}$ Institute of Molecular Biology, University of Oregon, Eugene, OR, USA. ${ }^{3}$ Institute of Molecular and Cell Biology, Singapore, Singapore. ${ }^{4}$ Humans and the Microbiome Program, Canadian Institute for Advanced Research, Toronto, ON M5G 1Z8, Canada. ${ }^{5}$ Present address: St. Edmund Hall, University of Oxford, Oxford, UK. Correspondence and requests for materials should be addressed to S.J. (email: sureshj@ntu.edu.sg)
} 
A large number of freshwater fish display a dramatic alarm response when exposed to conspecifics that have been injured $^{1-3}$. This change in emotional state, which is characterized by changes in locomotion, such as darting and freezing, involves the olfactory system ${ }^{4}$ and appears to be an adaptation to an indicator of potential danger. The alarm substance has been proposed to be produced by club cells ${ }^{5,6}$, which are unusually large cells located in the epidermis. This hypothesis is based on the observations that injury to the skin is sufficient to generate a response and that many species that produce an alarm substance possess club cells ${ }^{6}$. In addition, seasonal loss of club cells is correlated with loss of the alarm substance ${ }^{7}$. However, fish that have club cells do not necessarily produce a substance that causes fear in conspecifics 8,9 , indicating that club cells may have some additional function. The findings that the size of club cells increases in the presence of pathogens $s^{10,11}$ or polluted water ${ }^{12}$, while suppression of the immune system by cortisol causes a reduction in club cell numbers ${ }^{13}$, have led to the proposal that club cells function in epithelial stress ${ }^{12}$ or innate immunity ${ }^{10,13}$. It is unclear how an immune function for club cells relates to the alarm substance.

One possibility is that the alarm substance originates from a compartment of the skin that is directly linked to immunity, with club cells having a secondary role, such as storage. Several lines of evidence indicate that the alarm substance can be found in mucus. An alarm response can be elicited by material generated by vortexing fish ${ }^{14}$, a procedure that releases mucus. Biochemical characterization indicates that the alarm substance is a mixture that can be depleted from skin extract by wheat germ agglutinin (WGA), which binds mucus ${ }^{15-17}$, or an antibody to chondroitin sulfate $^{14}$, which is a component of mucus ${ }^{18}$. However, mucus evokes a strong response only after it has been heated ${ }^{14}$, implying that some form of breakdown is required. Mucus, which contains a diverse population of bacteria ${ }^{19}$, has multiple functions in fish skin, including defence against infectious agents ${ }^{20-22}$. Although mucus is produced by goblet cells, components of mucus such as glycosaminoglycans ${ }^{23,24}$ have been found inside club cells.

Here, we ask whether mucus is transported to club cells; given that bacteria are lysed by heat ${ }^{25}$, we also ask whether bacteria are also transported to club cells and test the hypothesis that bacteria provide a component of the alarm substance. We find that both bacteria and mucus are trafficked to club cells, with cell invasion playing a role. Our data establish that a substance from bacteria can function as an alarm substance, and provide insight into the evolution of the alarm response in fish.

\section{Results}

Mucus is transported into club cells. Club cells, which are large ovoid cells embedded in the epithelium (Supplementary Fig. 1), have no opening to the external surface ${ }^{6}$. We hypothesized that mucus may be trafficked indirectly from the surface to club cells. To test this, we performed a pulse chase experiment. Fish were transiently incubated in Alexa594-WGA to label mucus ${ }^{15,16}$, and imaged at various times subsequently to determine the fate of mucus. We used the nucleic acid dye SYTO 9 to label the epithelium. Except for the nucleus and perinuclear organelles, the cytoplasm of club cells is unlabeled by this dye and appears as dark areas; other cells, in contrast, are broadly labeled, with some heterogeneity in label according to cell type. After $2 \mathrm{~h}$ incubation in Alexa594-WGA, label was seen on surface epithelial cells, enriched on the apical ridges that have a high concentration of mucus, in puncta within superficial epithelial cells (as previously reported for larval peridem ${ }^{15}$ ), and goblet cells (Fig. 1a, b; Supplementary Movie 1; see Supplementary Fig. 1 for schematic diagram of zebrafish skin). No label was seen below the surface layer ( $n=3$ fish). Following a period of 1-2 days in clean water, label was still seen within all surface cells and in all goblet cells (Fig. 1c). In addition, WGA puncta were detected in deeper cells (Fig. 1d-f), and in 214/507 club cells (Fig. 1c; Supplementary Fig. 2; Supplementary Movie 2; $n=4$ fish). This suggests that mucus can be transported from the surface into club cells.

The presence of WGA puncta first within epithelial cells and goblet cells, and only subsequently inside club cells is consistent with transcytosis, which is a phenomenon that has been documented in the mucosal epithelium of other fish ${ }^{26}$. In addition to puncta, a few club cells contained an additional labeled cell (Fig. 1g-i). Club cells in several fish species, such as catfish and carp, have been reported to contain additional cells ${ }^{12,27-29}$, apparently as a result of cell entry. To verify that there can indeed be a second cell within club cells of zebrafish, we imaged zebrafish that had been labeled with SYTO 9, which labels nuclei acids and phalloidin, which labels cortical f-actin. As seen in Fig. 1j-o and Supplementary Movie 3, an additional cell can be found within the cytoplasm of zebrafish club cells. We noticed that the cytoplasm of some club cells that contained a second cell was diffusely labeled with Alexa594-WGA (Fig. 1p-x; Supplementary Movie 4). This suggests that cell entry could contribute to the presence of mucus within the cytoplasm of club cells.

Invasion giving rise to the cell-in-cell phenomenon has been reported in a number of tissues, including epithelia ${ }^{30,31}$. Invasion is an active process and contrasts with phagocytosis, which involves uptake of an apoptotic cell. Consistent with active invasion, we could detect internalized cells that were unlabelled by an antibody to cleaved Caspase-3 (Fig. 2a, b). There are several different forms of invasion, such as entosis ${ }^{32}$ and emperipolesis ${ }^{33}$. We first examined whether entry into club cells could involve entosis, a process that is dependent on cadherin-mediated adhesion, characterized by an accumulation of $\mathrm{f}$-actin at the rear end of in the invading cell ${ }^{34}$, and can lead to death of the intruding cell by autophagy in a noncell autonomous manner. No accumulation of $\beta$-catenin was seen at the interface between club cells and invading cells (Fig. 2 c; $n=4$ fish), and no accumulation of actin was seen at the rear end of the entering cell (Fig. $2 \mathrm{~d}-\mathrm{i}$ ), while LC3B label was detected within the internalized cell, rather than surrounding it (Fig. 2j). Another feature of entosis is that it involves homotypic internalization. We noted that the nuclear morphology of the internalized cell differed from that of club cells (Fig. 1j, k), indicating that this is heterotypic entry. Thus, entry into club cells may involve mechanisms distinct from entosis.

Further imaging indicates that the internalized cells are motile (Fig. 2k-m; Supplementary Movie 5; Supplementary Fig. 3), which is a feature of other forms of invasion, such as emperipolesis. Internalized nuclei were negative for $\Delta \mathrm{Np} 63^{35}$, which was detected in most epithelial cells (Fig. 2n-p). To test whether the cells include neutrophils, which are motile and invasive cells, we examined the $m p x$ :eGFP line ${ }^{36}$, in which neutrophils express eGFP under the control of the myeloperoxidase promoter. Neutrophils were strongly fluorescent in these fish (Fig. 2q), as were the cytoplasm of scattered club cells (Fig. 2r, s; Supplementary Movie $6 ; n=3$ fish). We thus propose that one cell type that can transfer material to club cells is neutrophils.

Bacteria are transported to club cells. Bacteria are known to produce substances that can stimulate chemosensory systems of vertebrates ${ }^{37-39}$. They are found within mucus of fish skin, and once inside the fish, can be engulfed by neutrophils ${ }^{40}$. These properties make bacteria potential components of an alarm signal that is transported from the surface into club cells. To test whether bacteria can be transported like mucus, fish were placed overnight in water containing chemically killed $E$. coli that had 

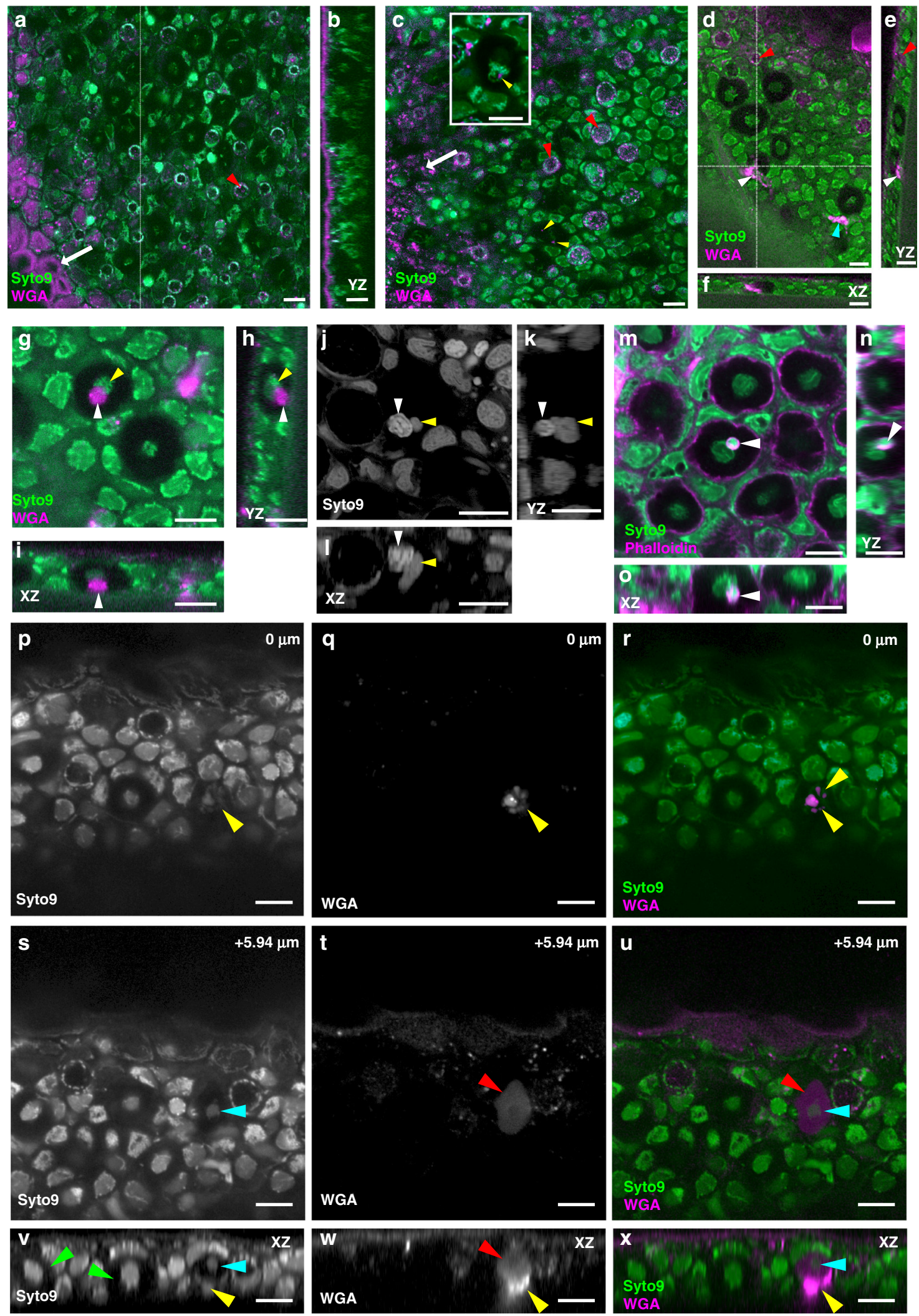

been labeled with a fluorescent dye pHrodo Red. The following day, punctate label was found in surface epithelial cells, goblet cells, neutrophils and club cells (Fig. $3 a-e ; n=6$ fish). Diffuse label was detected throughout the cytoplasm of a subset of club cells in all fish imaged $(11.6 \% \pm 6.6 \%$; average \pm standard deviation; $n=596$ cells; Supplementary Fig. 4; Fig. 3a;
Supplementary Movie 7). Repeated imaging suggests that this diffuse label is the result of transfer of material from an invading cell (Fig. 3f, g). Uptake into goblet cells, neutrophils and club cells was also seen with killed Staphylococcus aureus (Fig. 3h, i; $n=3$ fish; Supplementary Movie 8) and zymosan (Fig. 3j, k; $n=3$ fish). These results demonstrate that bacteria and other 
Fig. 1 Mucus is transported from the surface into club cells. a Oblique section through the skin of an adult zebrafish, after $2 \mathrm{~h}$ of incubation in Alexa594 WGA (magenta). Cells are visualized by SYTO 9 (green), which binds nucleic acids. WGA binding is visible on the surface (arrow), and in goblet cells (red arrowhead). b Reconstructed transverse section through a z-stack of the fish in a. WGA (magenta) is restricted to the surface. c Oblique section through the skin of a fish, after $2 \mathrm{~h}$ label in WGA followed by 2 days in clean water. Punctate label is visible in superficial cells (white arrow), goblet cells (red arrowheads) and in club cells (yellow arrowheads; see inset). d Oblique section through another fish after transient label with WGA and a 2-day chase, showing label in elongated cells (white and cyan arrowheads). e, $\mathbf{f}$ Reconstructed transverse sections through the $z$-stack of the fish in $\mathbf{d}$, showing the location of the labeled cell (white arrowhead) below a club cell. A superficial goblet cell is indicated (red arrowhead). g An Alexa594 WGA labeled cell (magenta; white arrowhead) inside a club cell. The club cell ER is indicated by the yellow arrowhead. $\mathbf{h}, \mathbf{i}$ Reconstructed transverse sections through the club cell with the second cell. j A SYTO 9 labeled fish. The white arrowhead indicates a second cell inside the club cell. The club cell nucleus (yellow arrowhead) is morphologically distinct. $\mathbf{k}$, I Transverse sections through the club cell. $\mathbf{m}$-o Alexa-568 Phalloidin labeling to visualize $\mathbf{f}$-actin. The club cell contains a second cell (white arrowhead) with cortical labeling. $\mathbf{n}$, o Transverse sections through the club cell. p-x Two different focal planes of the skin of a zebrafish, following transient label of mucus by Alexa594-WGA and 2 days incubation in clean water. p-r show a deeper plane of focus, with a WGAcontaining cell that may be blebbing (yellow arrowheads); s-u show a shallower plane with the club cell nucleus visible (cyan arrowhead). $\mathbf{t}$ The cytoplasm of the club cell is filled with Alexa594 WGA (red arrowhead). v-x Reconstructed transverse view through the $z$-stack. The club cell nucleus is indicated by the cyan arrowhead, while the WGA labeled cell is indicated by the yellow arrowhead. Club cells without internalized cells are indicated by the green arrowhead. Scale bar $=10 \mu \mathrm{m}$

particles can be taken into the skin of zebrafish and transported to club cells.

To test whether endogenous bacteria show a similar distribution, we performed in situ hybridization with an oligonucleotide probe to conserved sequences of bacterial $16 \mathrm{~S}$ rRNA $^{41}$. Label was seen in cells resembling neutrophils in all fields of view (Fig. 3l; $n$ $=27$ images in 11 fish; $3.6 \pm 2.5$ labeled cells (average \pm SD) per $156 \mu \mathrm{m} \times 156 \mu \mathrm{m}$ area). Club cells containing a second cell with associated puncta (Fig. 3n-q; Supplementary Movie 9), or that was fully labeled (Fig. 3s), were also detected. The pattern is consistent with the hypothesis that endogenous bacteria are transported with mucus into club cells, potentially involving invasion of neutrophils.

Bacterial lysate elicit a change in behavior. Given the presence of bacteria in mucus and in club cells, we asked if bacteria could contribute to the alarm substance. To that end, we used a panel of diverse bacteria, including Gram-negative and Gram-positive strains that had been isolated from laboratory zebrafish and for which complete genome sequences have been determined ${ }^{42}$, and one human isolate (see Supplementary Table 1). The bacteria were grown in culture, and then lysed by heating and the bacterial lysates were tested on individual fish. Of the ten strains tested, one strain-the Gram-positive Staphylococcus saprophyticus (ZWU0021) ${ }^{42}$-evoked a prolonged freezing response in two out of four tester fish (Fig. 4a, b, e; Supplementary Fig. 5). This bacterial lysate also caused fish to move to the base of the tank, which is typical of alarm behavior ${ }^{14}$ (Fig. 4c, d, f; Supplementary Fig. 6). Other bacterial lysates (Pseudomonas aeruginosa, Kocuria sp. and Aeromonas sp.) gave a weaker effect, e.g., freezing for shorter durations or movement to the tank base without freezing, whereas lysates from the remaining bacterial strains did not elicit any obvious change in behavior. Darting behavior was limited (Fig. 4g). To obtain an indication of the responsiveness of the tester fish that did not react to the lysate (to rule out false negatives), nonresponders were exposed to skin extract. 20 out of 30 such fish froze to skin extract, demonstrating that they could detect the alarm substance. These observations establish that lysis of a subset of commensal bacteria releases a substance that is capable of eliciting behaviors that are characteristic of the alarm response.

Detection of the alarm substance has been shown to involve the olfactory system. We asked whether bacterial lysates can signal via the same olfactory receptors as the skin-derived substance. In general, each olfactory sensory neuron expresses a single or a few receptors, and all neurons with the same receptor combination project to the same glomerulus. To compare receptor binding of fish extract and bacterial lysates, we thus imaged glomeruli. Previous imaging of larval zebrafish with broad expression of a calcium indicator suggested that the active fraction of skin extract strongly activates a dorsolateral glomerulus ${ }^{14}$. The responding neurons include microvillous neurons, as skin extract evoked a response in the dorsolateral bulb of $\operatorname{Tg}(\operatorname{trp} C 2: G A L 4, U A S$ : GCaMP6s) (Fig. 5a, b) but not Tg(OMP:GAL4, UAS:GCaMP6s) fish. A response to skin extract was also seen in the $T g$ (gng8: GAL4, UAS:GCaMP6s) line, which labels a subset of microvillous $\mathrm{OSNs}^{43}(5 c, d)$. Lysates from commensal bacteria did not activate OSNs innervating the dorsolateral glomerulus (Fig. 5e, f), but did elicit a response in OSNs terminating more ventrally (Fig. $5 g$, h, i). A survey of the response of lysates from several different strains indicated that Staphylococcus sp ZWU0021 elicited a response that was more similar to skin extract, compared with another Gram-positive bacterium Kocuria sp ZOR0020, or to the Gram-negative Aeromonas sp ZOR0001 (Fig. 5j).

The absence of a response in the dorsolateral glomerulus to the bacterial lysate raises the question of whether bacteria are the sole source of the alarm substance. One potential method to address this could be to test the effect of skin extracts from adult fish that have been treated with antibiotics. However, this treatment is relatively inefficient at eliminating bacteria. Although there is a reduction in the bacteria population in the skin (Supplementary Fig. 7a-d), some bacteria remain, and the population reestablishes itself relatively quickly (Supplementary Fig. 7e, f). Also, any bacteria derived products that are stored in the fish would not be eliminated with this approach. Thus, a better method would be to use fish that are germ-free from embryonic stages. We opted to work with larval fish, as obtaining healthy germ-free larval fish is more straightforward, given that there is no need for an external food source ${ }^{44}$. We first showed that lysates prepared from fish aged 7-8 dpf were able to evoke alarm behavior in adult zebrafish (Supplementary Fig. 8a-c), and elicit activity in the dorsolateral glomerulus (Supplementary Fig. 8d, e), indicating that an alarm substance can be derived from larvae. This set the stage for comparing the effects of lysate from germfree versus conventional fish.

Like lysates from conventional fish, lysates prepared from germ-free larval fish could elicit alarm behavior (Fig. 6a), as judged by increased darting (Fig. 6d) and time spent at the tank base (Fig. 6c). The mean increase in time spent darting with germ-free lysate was 7.33 s [95\%CI $2.33,12.3]$, similar to the time of $8.83 \mathrm{~s}$ [95\%CI $4.67,12.2$ ] evoked by conventional lysate. The proportion of time spent in the lower third of the tank after lysate delivery, compared with before lysate delivery, increased by 0.318 [95\%CI 0.107, 0.467] for germ-free fish; this is similar to the 



Fig. 2 Characterization of cell invasion in zebrafish skin. $\mathbf{a}, \mathbf{b}$ Labeling for cleaved Caspase-3. a The second cell within a club cell (white arrowhead) is unlabelled. $\mathbf{b}$ An example of a labeled skin cell (yellow arrowhead). c Label for $\beta$-catenin. In contrast to superficial epithelial cells, which have an enrichment of $\beta$-catenin at the periphery (white arrowhead), no enrichment is detectable in cells entering (red arrowhead) or within (yellow arrowhead) club cells. d Phalloidin label for f-actin. A strongly labeled cell (yellow arrowhead) is visible at the edge of a club cell. e, $\mathbf{f}$ Transverse sections through cell in d, showing the peripheral position of the cell relative to the club cell. $\mathbf{g}$ A fish expressing Lifeact-GFP in a motile cell that appears to be extending a protrusion into a club cell. $\mathbf{h}$, $\mathbf{i}$ Transverse sections through the center of the club cell. The skin was labeled with 4-Di-2-ASP, which leaves most the club cell cytoplasm unlabelled. The invading cell is located near the base of the epithelium. $\mathbf{j}$ Label for LC3B is detected within the second cell (white arrowhead), but not surrounding it. $\mathbf{k}-\mathbf{m}$ Three different time points of the skin of a fish expressing Lifeact-GFP in cell that appears to be mostly inside a club cell (arrowhead), but with protrusions extending outside. The insets show surface rendering of the green fluorescence across the $z$-stack. The cell changes shape over the period of imaging. $\mathbf{n}$-p Label for $\Delta \mathrm{Np} 63$ (magenta). No signal was detected in cells invading club cells (yellow and red arrowheads). $\mathbf{q}, \mathbf{r}$ Two different focal planes of a fish with neutrophils expressing GFP under the control of the mpx promoter. Neutrophils are strongly fluorescent. The cytoplasm of a subset of club cells is weakly labeled; the cyan arrowhead indicates an unlabelled club cell. $\mathbf{s}$ Transverse section through a labeled club cell (yellow arrowhead) and neutrophil (white arrowhead). Scale bar $=10 \mu \mathrm{m}$ 

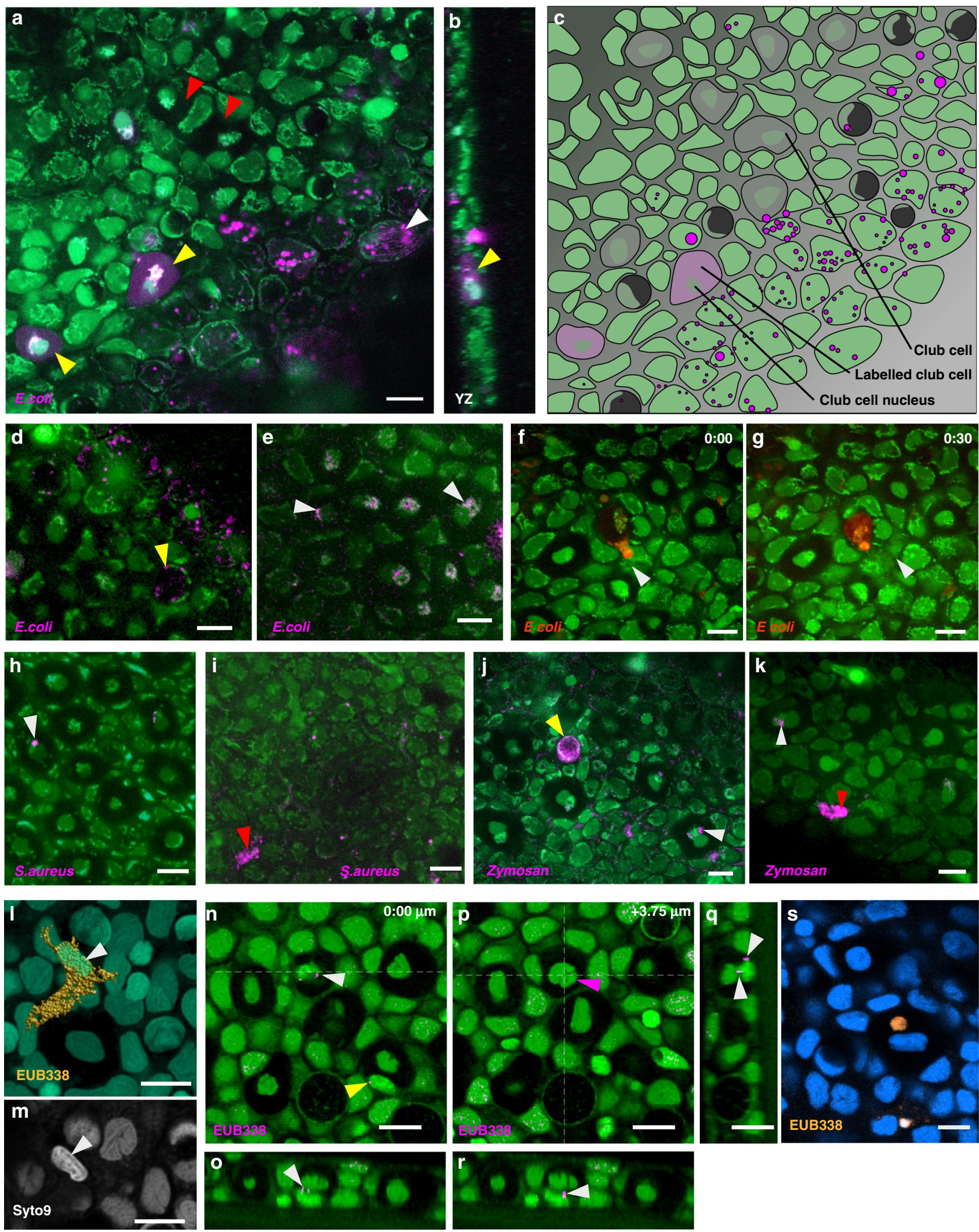

change of 0.263 [95\%CI $-0.181,0.593]$ for conventional fish. Therefore, both germ-free and conventional lysates are able to evoke darting and bottom-dwelling behavior. In contrast, the extent of freezing was lower for germ-free lysate (Fig. 6b), with conventional lysate causing an average of $204.5 \mathrm{~s}$ freezing [ $95 \% \mathrm{CI}$ $172.3,228.5]$ compared with the $59.8 \mathrm{~s}$ [95\%CI 8.0, 164.0] evoked by germ-free lysate. To further examine the effect of bacteria, the effect of lysates from germ-free fish was compared with that of conventional fish and germ-free fish that had been monoassociated with Staphylococcus ZWU0021. Again, germ-free lysate induced less freezing (Fig. 6f). These observations demonstrate that a fish component can evoke alarm behavior, particularly 
Fig. 3 Bacteria are transported to club cells. a An oblique section through the skin of a fish after overnight incubation in pHrodo Red labeled E. coli. The cytoplasm of two club cells is diffusely labeled (yellow arrowheads); other club cells do not have this diffuse pHrodo red fluorescence in their cytoplasm (red arrowheads). See Supplementary Movie 7. b A transverse section through the z-stack in a, showing one labeled club cell (yellow arrowhead). c.A schematic diagram of the slice in panel a, showing the different cell types. d Oblique section through the skin of another fish after overnight incubation in pHrodo Red labeled E. coli. Puncta are visible in goblet cells (arrowhead). e Localization of pHrodo Red labeled E. coli to perinuclear organelles of club cells (arrowheads). $\mathbf{f}, \mathbf{g}$ Entry of a cell carrying pHrodo Red labeled E. coli into a club cell. $\mathbf{f}$ The cell (arrowhead) is initially adjacent to the club cell, but appears to have transferred some of its cytoplasm into the club cell. $\mathbf{g}$ After $30 \mathrm{~min}$, the cell appears to be inside the cytoplasm of the club cell, which is now more intensely labeled. Localization of pHrodo red labeled S. aureus $(\mathbf{h}, \mathbf{i})$ and zymosan $(\mathbf{j}, \mathbf{k})$ within the epithelium, after transient incubation. I A neutrophil with bacteria, visualized by the EUB338 probe. Fish cells are labeled with SYTO 9 (green). This is a surface rendering of a $z$-stack, showing all focal planes. $\mathbf{m}$ A single plane of the stack in panel l, showing SYTO 9 label. The nucleus of the neutrophil (arrowhead) resembles the cell seen inside the club cell in Fig. 1e. $\mathbf{n}, \mathbf{p}$ Two different focal planes of a region of the skin following in situ hybridization with the EUB338 probe. $\mathbf{n}$ At a deeper plane, several puncta are visible (white arrowhead), associated with a nucleus. One puncta is also associated with a second cell in a neighboring club cell (yellow arrowhead). $\mathbf{o}$ Transverse section through the club cell in $\mathbf{n}$, with two puncta visible (arrowhead). p A shallower focal plane, showing the characteristic bi-lobed nucleus of a club cell (magenta arrowhead). $\mathbf{q}, \mathbf{r}$ Transverse sections through the $z$-stack in $\mathbf{p}$, showing labeled puncta associated with the deeper cell (arrowheads). $\mathbf{s} A$ rounded cell inside a club cell, labeled with probe to $16 \mathrm{~S}$ rRNA. Scale bar $=10 \mu \mathrm{m}$

darting, independent of bacteria, but also suggest that the alarm substance is most effective when both bacteria and fish are present, consistent with previous reports that the alarm substance is a mixture ${ }^{14,45}$.

\section{Discussion}

Club cells in the skin of fish have been proposed to function in immunity ${ }^{10}$ and also in production of the alarm substance ${ }^{6,7}$. The data here are consistent with club cells having a role in host defence, and suggest that this is linked to storage of the alarm substance. Superficial epithelial cells and goblet cells readily internalize mucus and bacteria that are on the surface, as indicated by experiments with labeled WGA, E. coli and S. aureus. These are then transferred to club cells. The process may involve transcytosis or transfer by immune cells, such as neutrophils; the possibility that transfer occurs via other cells cannot be discounted, as previous EM studies indicate that several different cell types can be found in club cells ${ }^{28}$. The reason for such transport is unclear at present, but an intriguing possibility is that club cells function at the interface between innate and adaptive immunity, possibly as antigen presenting cells. This could play a role in tolerance of commensal bacteria, as in the gut ${ }^{46}$. The ability of neutrophils to transfer their cytoplasmic contents has been reported in a few cases-for example, proteins can be transferred from neutrophils to endothelial cells ${ }^{47}$ or to $\mathrm{T}$ cells ${ }^{48}$. In these cases, transfer requires direct contact, with the neutrophils remaining outside the target cell. In the zebrafish skin, transfer can begin when neutrophils are outside club cells, as indicated by observations in the fish containing labeled E. coli. However, cell invasion also occurs, and may represent an additional mechanism by which material from the surface is delivered to club cells. Given the motility of the internalized cell, some invasion may occur via a process resembling emperipolesis 49,50

In principle, any substance that enters surface epithelial cells or goblet cells can be re-exported and transported to club cells, where it is accumulated and can serve as an alarm substance. It has previously been shown that an alarm response can be evoked by mucus that had been briefly digested with chondroitinase $\mathrm{ABC}^{14}$. Although this was interpreted as evidence for chondroitin fragments being a component of the alarm substance, chondroitin sulfate only elicited weak behavior effects. An alternative interpretation of the data is that other molecules, such as metabolites that are present in mucus ${ }^{51}$, may be transported to club cells. When club cells are ruptured, these could act together with the bacterial component as Schreckstoff. It is notable that the bacterial lysates evoked freezing and movement to the tank base, but did not cause much darting. This is in contrast to the extract from germ-free fish, which caused darting, but not much freezing. In previous work, we had shown that different components of the alarm substance contribute to different aspects of the behavior ${ }^{14}$ raising the intriguing hypothesis that freezing may be evoked by bacteria, whereas the fish-specific component of Schreckstoff evokes darting. These components may act via different circuits. For example, the fish-specific component may act via olfactory neurons terminating in the dorsolateral bulb, as indicated by calcium imaging. While bacterial lysate can also be detected by the olfactory system, we speculate that they may additionally be sensed by other chemosensory neurons, such as solitary chemosensory cells, which are tuned to mucus in a species-specific manner and innervate the brainstem to provide an alternative neural pathway for defensive behavior ${ }^{52}$.

There has been some debate as to how production of the alarm substance was selected for in evolution, as the substance was released only upon injury or death of the sender, who would derive no benefit ${ }^{53}$. Kin selection appears to be uninvolved, as responding fish are not necessarily related to the sender ${ }^{54}$. Better support was provided for the predator attraction hypothesis, which proposes that the substance attracts secondary predators and provides an opportunity for the sender to escape ${ }^{55,56}$ However, it was uncertain how effective this could be in practise $\mathrm{e}^{57}$, and not all predators respond to the alarm substance of prey $^{58}$. The data here suggest that the alarm substance could have evolved as a result of processes involved in mucosal immunity. Accumulation of mucus and bacteria inside club cells would lead to a build-up of the material that is released only upon injury, i.e., a suitable proxy for danger. This view is consistent with the correlation between the amounts of alarm substance and number of club cells ${ }^{7}$. The observation that whole larvae that have no club cells are still able to produce an alarm substance ${ }^{59}$ may be due to the presence of mucus and bacteria in the skin and the gut.

The ability of bacteria to influence the vertebrate nervous system is well established, especially via the gut-brain axis. There is some evidence that bacteria could contribute to social olfactory signaling in other species (e.g., hyenas ${ }^{60}$ ), but a causal relationship in vertebrates has not been demonstrated. The data here establish that substances from commensal bacteria from one individual are capable of acutely influencing the emotional state of others. Instead of originating only from a dying host, i.e., serving a purely altruistic role, we suggest that the alarm signal derives from mechanisms that protect the host. The production and response to Schreckstoff thus involve processes that are beneficial to the individual and to the species.

\section{Methods}

Ethical statement. The experiments described here were carried out in accordance with the guidelines and protocols approved by the IACUC of the Biological 
$\mathbf{a}$

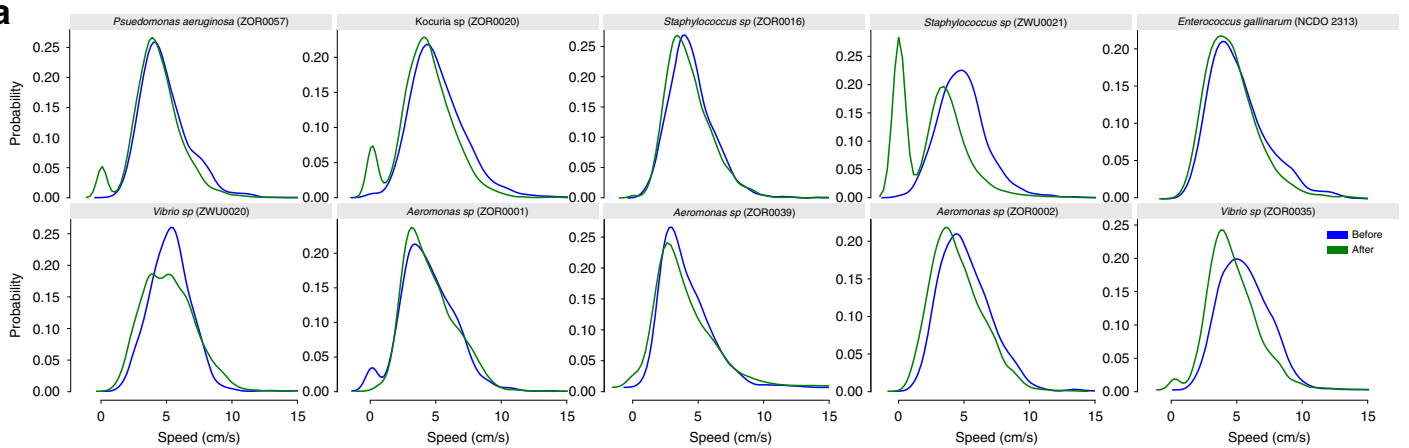

b
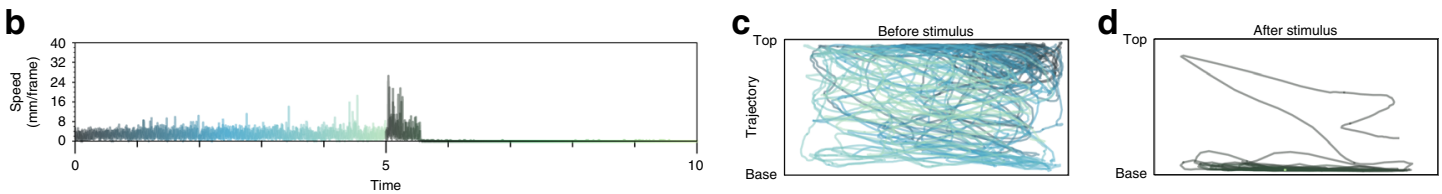

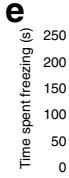
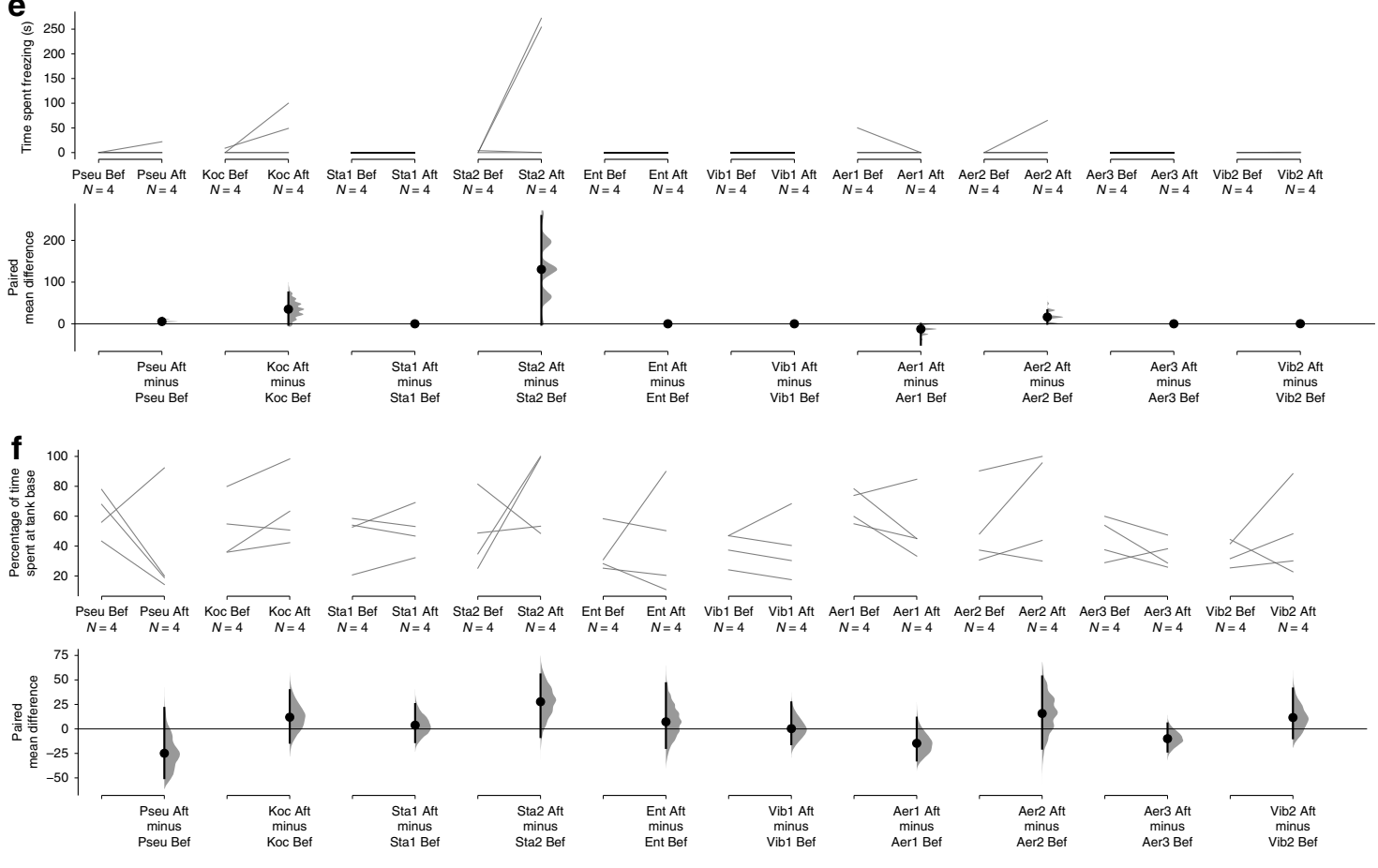

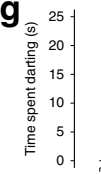

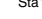

Vib1 1 e

$\underset{\substack{\text { minus } \\ \text { Aerr Bet }}}{ }$

minus
Aer2 Bef

Vib2 Ber

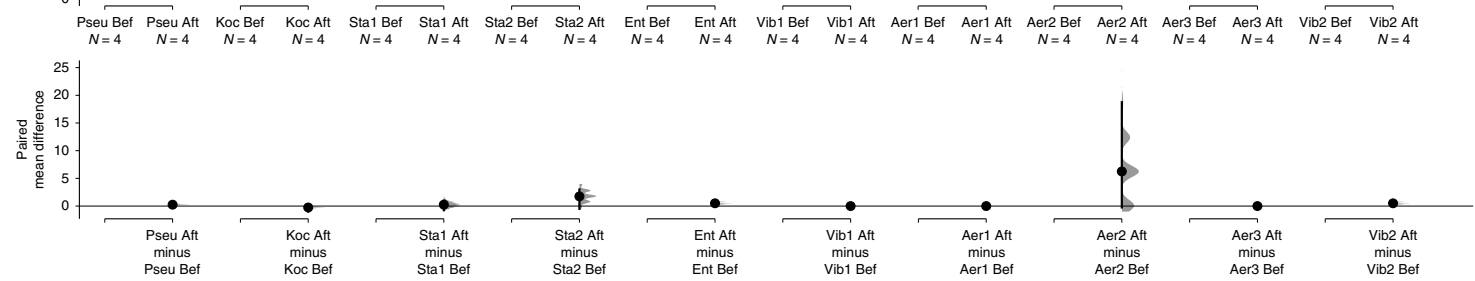

Fig. 4 Effect of commensal bacteria on zebrafish behavior. a Effect of lysates from ten different cultured bacteria on behavior of adult zebrafish, as indicated by probablity density function of speed before (blue) and after (green) application of the lysate. b-d Response of one fish to lysate from the bacteria Staphylococcus sp. ZWU0021. b Speed of the fish. The trace is color coded according to time, with dark gray indicating the delivery of the lysate. Position of the fish, before (c) and after (d) stimulus. Effect of bacterial lysate of adult fish, as indicated by time spent freezing (e), percentage of time at tank base (f), and time spent darting ( $\mathbf{g})$, as shown by Cumming estimation plots ${ }^{72}$. The raw data are plotted on the upper axes and each paired set of observations (before (Bef) and after (Aft) delivery of bacterial lysate) is connected by a line. On the lower axes, each paired mean difference is plotted as a bootstrap sampling distribution. Mean differences are depicted as dots; $95 \%$ confidence intervals are indicated by the ends of the vertical error bars 

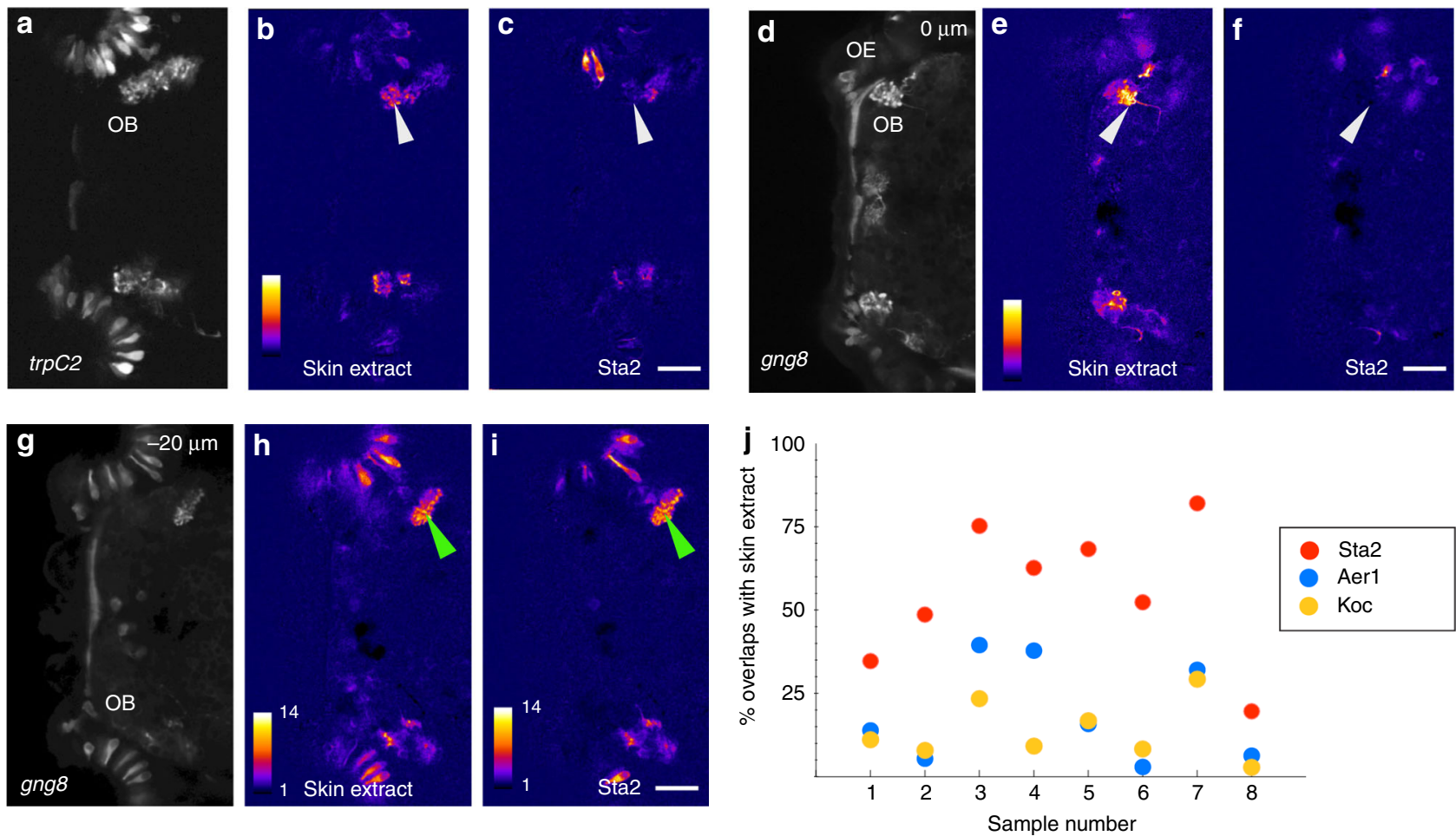

Fig. 5 Effect of bacterial lysate on the olfactory system. $\mathbf{a}-\mathbf{i}$ Calcium imaging of the olfactory bulb two different larval fish exposed to skin extract (b, e, h) or bacterial lysate $(\mathbf{c}, \mathbf{f}, \mathbf{i})$. Average projection of the time-series, showing GCaMP6s expression in olfactory sensory neurons and in terminals, driven by the trpc2 (a) or gng8 ( $\mathbf{d}, \mathbf{g})$ promoter. Panels $\mathbf{d}-\mathbf{i}$ are the same fish, with $\mathbf{g - i}$ showing a plane that is $20 \mu \mathrm{m}$ deeper than $\mathbf{d}-\mathbf{f}$. A glomerulus in the dorsal bulb (white arrowhead) is activated by skin extract but not by the bacterial lysate. Both lysates activate identical terminals in the ventral bulb (green arrowhead). j Percentage of overlap between response to three different bacterial lysates and skin extract. The highest overlap is seen with lysate from Staphylococcus sp. ZWU0021. Anterior is to the left; OB olfactory bulb, OE olfactory epithelium. Scale bar $=25 \mu \mathrm{m}$

Resource Center at Biopolis, Singapore (\#151092) and by the IACUC of the University of Oregon (\#15-98).

Fish lines. The transgenic lines used were: $\operatorname{TgBAC}(g n g 8: G A L 4 F F) c 426^{61}, \operatorname{Tg}(\operatorname{trp} C 2$ : GAL4)p20962, $T g(O M P: G A L 4 F F) r w 0320^{63}, T g(U A S: G C a M P 6 s) s q 205$, and $T g$ (actb2:LIFEACT-GFP)e114. The e114 line labels motile cells in the skin of adult fish (Supplementary Movie 10).

$\operatorname{Tg}($ nbt:jGCaMP7f)sq214 was generated using Gateway cloning. The coding sequence for jGCaMP7f was amplified from pGP-CMV-jGCaMP7f (a gift from Douglas Kim; Addgene plasmid \#104483) using Phusion High-Fidelity DNA Polymerase. This was placed downstream of the $3.8 \mathrm{~kb}$ Xenopus laevis neural beta tubulin (Xla.Tubb) promoter, in a Tol2 plasmid, and injected into embryos at the 1-cell stage together with Tol2 transposase mRNA.

Culture and lysis of commensal bacteria. Bacterial strains were obtained as described by Stephens et al. ${ }^{42}$, except for Enterococcus gallinarum, which was obtained from ATCC (strain 49573). All strains were maintained in 25\% glycerol at $-80^{\circ} \mathrm{C}$. Most bacteria were directly inoculated into $5 \mathrm{~mL}$ Tryptic Soy Broth media (BD 211825) and grown for $\sim 16 \mathrm{~h}$ (overnight) with shaking at $30^{\circ} \mathrm{C}$. Kocuria $s p$, Staphylococcus strains, and Enterococcus gallinarum were grown for $\sim 16 \mathrm{~h}$ (overnight) in Brain Heart Infusion Broth media (BD B237500) at $30^{\circ} \mathrm{C}$ with shaking, except Staphylococcus sp ZOR0016, which was grown stagnant.

Bacterial cultures were washed twice; once by centrifugation, aspiration of supernatant, and suspension in $0.7 \% \mathrm{NaCl}$, and a second time by centrifugation, aspiration of supernatant, and suspension in a volume of sterile water equal to starting volume. Cell solutions were heated at $90^{\circ} \mathrm{C}$ for $30 \mathrm{~min}$ to lyse bacteria. Cell debris was pelleted by centrifugation and the supernatant was filter sterilized with a $0.2 \mu \mathrm{m}$ filter. Lysates were stored at $4^{\circ} \mathrm{C}$.

Staphylococcus sp ZWU0021 (IMG genome ID 2526164573) was classified by BLAST searches with the $g y r B^{64}$ and $r p o B^{65}$ genes.

Production of skin extract. Fish were euthanized in iced water before being placed in a clean petri dish, where shallow cuts were made to both sides of the fish with a sharp razor (Sharpoint, $\left.22.5^{\circ} \mathrm{stab}\right)$. The cut fish was put into a $2 \mathrm{~mL}$ tube with filtered $\mathrm{E} 3\left(5 \mathrm{mM} \mathrm{NaCl}, 0.17 \mathrm{mM} \mathrm{KCl}, 0.33 \mathrm{mM} \mathrm{CaCl}_{2}\right.$, and $\left.0.33 \mathrm{mM} \mathrm{MgSO}_{4}\right)$ and placed on a rocking platform shaker for $5 \mathrm{~min}$. After discarding the fish, the liquid was topped up to $2 \mathrm{~mL}$ with E3 and heated at $95^{\circ} \mathrm{C}$ for $2 \mathrm{~h}$. Heated extract was placed on ice to cool before spinning at $10,000 \mathrm{rpm}$ for $10 \mathrm{~min}$. The supernatant was pooled from multiple fish before using in behavior assays.

Generation of larval extract. Lysates comprising unfed 7 or $8 \mathrm{dpf}$ larvae were generated at a final concentration of 1 larva per $20 \mu \mathrm{L}$ E3 media, on a laboratory benchtop under sterile conditions. First, a cell culture strainer immersed in a petri dish of sterile E3 media was used to concentrate the larvae. After a brief wash (i.e. transfer into another petri dish of sterile E3), larvae were moved to a $1.5 \mathrm{~mL}$ Eppendorf tube using a sterile transfer pipette, and anaesthetized on ice. After larvae had sunk to the bottom, most of the E3 was removed (leaving $\sim 200 \mu \mathrm{L}$ in the tube), and a sterile plastic pestle attached to a motor-driven grinder was used to thoroughly homogenize larvae for $\sim 1 \mathrm{~min}$ The homogenized larvae were subsequently heated for $30 \mathrm{~min}$ on a $95^{\circ} \mathrm{C}$ heat block (this heating step serves as a control for bacteria lysate experiments, but is unnecessary for the generation of an alarm response). Afterwards, the heated extract was centrifuged at 13,000 rpm for 5 min The supernatant was then transferred into a clean tube, and additional sterile E3 was added to make up the final volume of 1 larva per $20 \mu \mathrm{L} \mathrm{E3}$. Larval lysates were stored at $4{ }^{\circ} \mathrm{C}$ until ready to use. They are effective for at least a few weeks.

Behavior assay and analysis. Testing of alarm behavior was conducted on TLEK wild types in a glass tank measuring $20 \mathrm{~cm}(\mathrm{~L})$ by $5 \mathrm{~cm}(\mathrm{~W})$ by $12 \mathrm{~cm}(\mathrm{H})$ containing $1 \mathrm{~L}$ of aquarium water. Naive fish more than 2 months old were habituated in the tank for 5-7 min before each test, and then recorded for $5 \mathrm{~min}$ before substance delivery and $5 \mathrm{~min}$ after substance delivery. Substances were manually pipetted into the tank, where $5 \mu \mathrm{L}$ of test substance was diluted in $1 \mathrm{~mL}$ fish water before delivery. The alarm response is known to be highly variable and some batches of zebrafish do not respond reliably. Hence, as a control, skin extract was delivered to fish that did not respond to the test substance after the 10-min recording session. Typically, $\sim 70 \%$ fish would respond to skin extract, and the entire set was discarded if the percentage of responders in a population was lower than $50 \%$. No response was seen when fish water was delivered.

For video recording, tanks were placed in front of a black background with overhead lighting in a darkened room. Videos were recorded from the front at 30 frames per second by a Basler USB3 camera in a resolution of $1680 \times 480$ pixels for filming two tanks simultaneously. The position ( $x-y$ coordinates) of the fish was determined online based on background subtraction algorithms in Python utilizing OpenCV library. These data were then analyzed offline for speed and other measures. Fish speed was binned by $\mathrm{cm} / \mathrm{s}$ over the 5 -min period before and after 
a

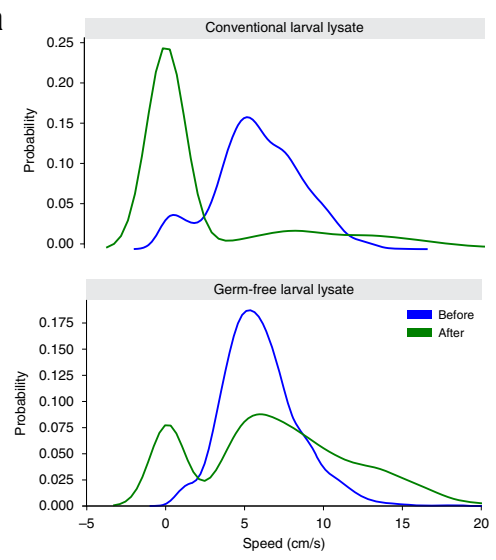

$\mathbf{e}$
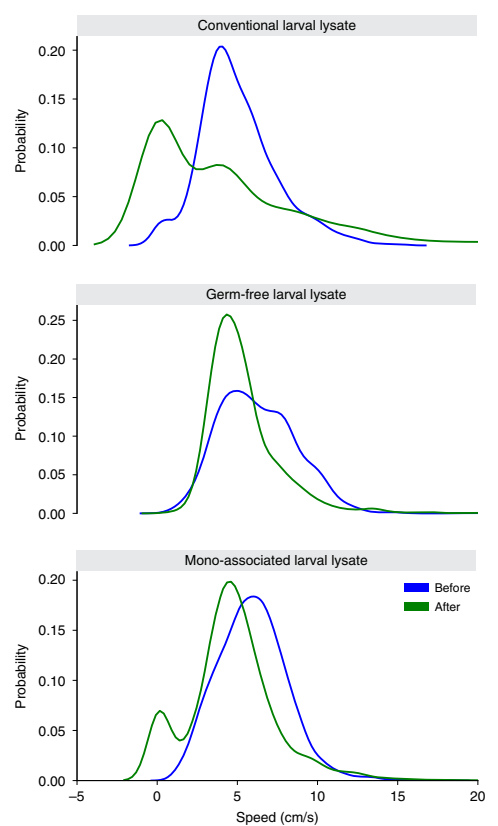

b
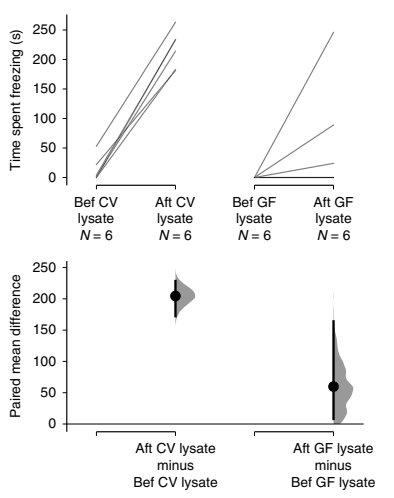

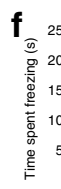

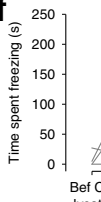

Bercilysa

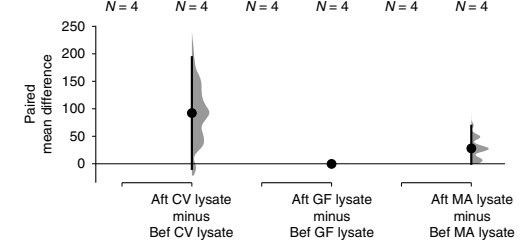

h
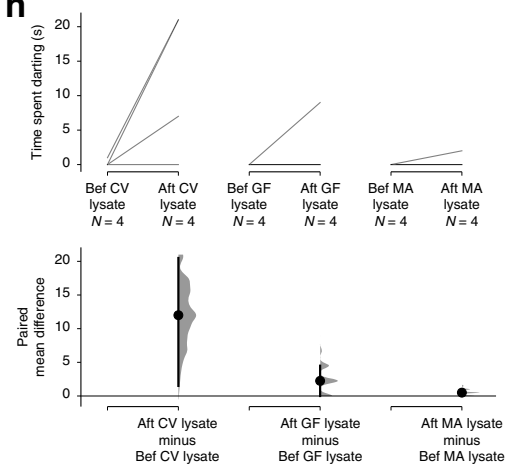

C
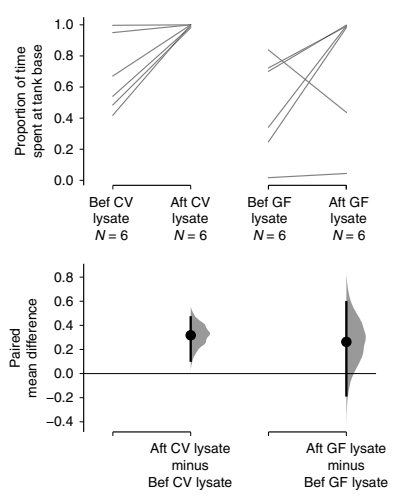

g
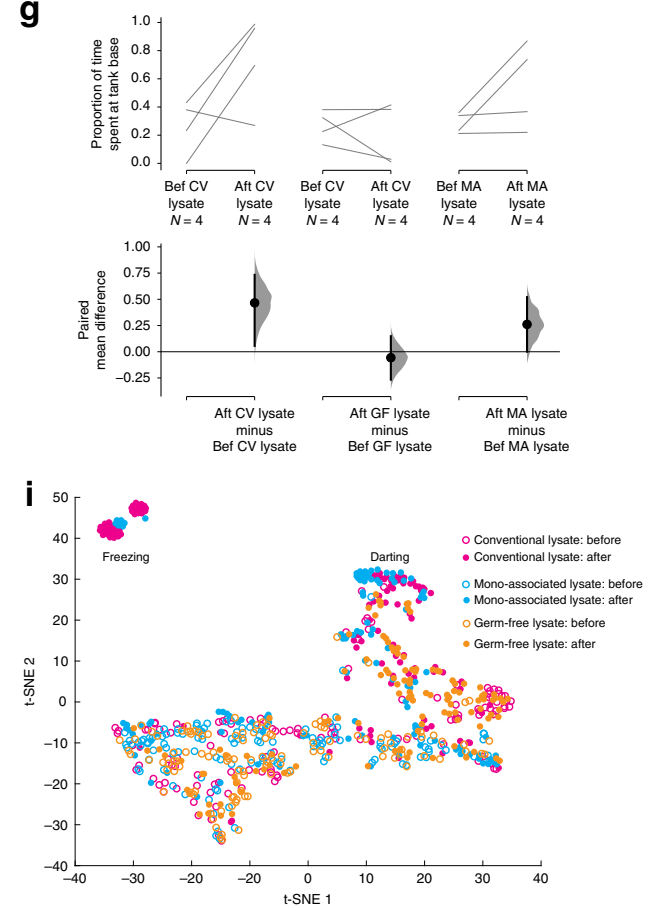

Fig. 6 Fish and bacteria provide components of the alarm substance. Effect of lysate from conventional (CV) and germ-free (GF) larvae on behavior of adult zebrafish ( $n=6$ each), as shown by speed probability density function (a), and change in freezing (b), time spent at the tank base (c), and darting (d). e-h. Effect of lysate from a separate batch of conventional (CV), germ-free (GF), and monoassociated (MA) larvae on behavior of adult zebrafish ( $n=4$ each). i Swimming behavior was clustered using t-distributed stochastic neighbor embedding (t-SNE). Each data point represents behavior within a $5 \mathrm{~s}$ epoch. Filled circles indicate behavior that occurs after delivery of the lysate. The response to lysate from conventional is monoassociated larvae (blue and red circles) are more similar than the response to lysate from germ-free larvae (orange circles). The cluster on the top left corner corresponds to prolonged freezing behavior, which was not evoked by lysate from germ-free fish. Other postlysate clusters may represent darting behavior

the substance was delivered and plotted in a histogram. The probability density function for the before and after periods were superimposed to show the effect of the substance on fish speed.

For t-SNE-based clustering of behavior (MATLAB), eight features were extracted from $x-y$ coordinates: (1) Distance, (2) velocity, (3) acceleration, (4) absolute tank depth, (5) change in tank depth, (6) horizontal translation, (7) posture (i.e., width/height of bounding box), and (8) change in posture. The mean, minimum, maximum. and standard deviations of these features were then quantified across $5 \mathrm{~s}$ (150 frame) epochs for the entire length of the experiment (both before and after lysate presentation) and aggregated across 12 fish (four fish from each treatment of conventional, germ-free, and monoassociated fish lysates, respectively) in an $8 \times 4=32$ dimensional array. t-SNE was then applied for dimensionality reduction to two dimensions (MATLAB default parameters: https://www.mathworks.com/help/stats/tsne.html).

Calcium imaging. Two photons imaging at $1 \mathrm{~Hz}$ were carried out using a galvano scanner on a Nikon A1R-MP system attached to a FN1 microscope with a 25x water dipping objective and the Ti Sapphire laser tuned to $930 \mathrm{~nm}$. Widefield imaging was performed using a Zeiss Axio Examiner with a $20 \times$ water dipping objective. Images were captured with a Hamamatsu Flash C4, controlled by MetaMorph. Illumination was provided by a blue LED (Cairn). Larval fish were anesthetized in mivacurium, and then embedded dorsal up in $2 \%$ agarose in E3 on a glass coverslip held in a Warner chamber. A wedge with an angle of $\sim 120^{\circ}$ was cut in front of the fish, which was then placed within in a diamond flow chamber (Warner R26). Stimuli were delivered using a perfusion device (Warner VC-6M) controlled by TTL pulses from the Elements or MetaMorph software.

Images were analyzed using FIJI software ${ }^{66}$. After registration to correct for $x-y$ drift, using the StackReg plug-in with the translation option, a running average of three frames was carried out. The change in fluorescence intensity (F/F0) was then obtained, using the ten frames prior to stimulus delivery as a baseline. Images show the frame with the maximum increase in fluorescence. For display, the "fire" LUT was used, with level set to a center of 5.69 and width of 10.67 in all images.

To compare the extent of OSN activation, the area of pixels with more than twofold increase in fluorescence was compared. The area of overlap between the 
different stimuli was then measured, and represented as a percentage of the area with a response to skin extract.

Adult antibiotic treatment. Adult zebrafish from the same home tank were treated with a final concentration of $25 \mu \mathrm{g} / \mathrm{mL}$ rifampicin ${ }^{67}$ for 5 or $18 \mathrm{~h}$. The $50 \mathrm{mg} / \mathrm{mL}$ rifampicin stock was dissolved in DMSO before 1:2000 dilution in fish water. A $1 \mathrm{~L}$ crossing tank filled with $500 \mathrm{~mL}$ of rifampicin or fish water was used to treat fish. Fish were then netted with an autoclaved net and transferred into a $50 \mathrm{~mL}$ falcon tube containing filtered Tricaine ( $300 \mathrm{mg} / \mathrm{L}$, for euthanasia). To obtain mucus layer, euthanised fish were transferred into a $50 \mathrm{~mL}$ tube containing $2 \mathrm{~mL}$ filtered E3 per fish and vortexed for $1 \mathrm{~min}$ with a break every $10 \mathrm{~s}$. The supernatant was collected to test for the presence of bacteria by plating on LB or ARISA.

Swab sample and DNA purification. Fish were anesthetized in sterile-filtered E3 with Tricaine (Sigma, USA) and swabbed on both sides using sterile cotton swabs (LP Italiana, Italy). Each swab was incubated individually in $1.5 \mathrm{~mL}$ microcentrifuge tubes containing $300 \mu \mathrm{L}$ of filtered $\mathrm{E} 3$, for $30 \mathrm{~min}$ at room temperature. Solutions were filtered through a Minisart ${ }^{\circledR} 0.2 \mu \mathrm{m}$ syringe filter (Sartorius, Germany). Following incubation, the cotton swabs were squeezed of any remaining liquid and disposed. Each of the $1.5 \mathrm{~mL}$ microcentrifuge tubes was topped up to 1 $\mathrm{mL}$ with filtered $\mathrm{E} 3$ and then combined into a single tube. DNA was extracted and purified from $100 \mu \mathrm{L}$ of the swab sample by treatment with sodium hydroxide, EDTA, and ethanol ${ }^{68}$, which allows for extraction from both gram-positive and gram-negative bacteria.

ARISA conditions and primers. The universal primers used for ARISA PCR were 1406F: 5'-TGYACACACCGCCCGT-3' and 23Sr: 5'-GGGTTBCCCCATTCRG-3'69. $2 \mu \mathrm{L}$ of the purified DNA sample was used for each $25 \mu \mathrm{L}$ reaction containing $1 \times$ Taq Buffer (Thermo Fisher Scientific, USA), $1 \mathrm{mM}$ of $\mathrm{MgCl}_{2}, 2.5 \mathrm{U}$ of Taq DNA polymerase, $0.2 \mathrm{mM}$ (each) deoxynucleoside triphosphate (Promega, USA), and $0.25 \mu \mathrm{M}$ (each) primer. The PCR conditions performed were as follows: $95^{\circ} \mathrm{C}$ for $3 \mathrm{~min}, 30$ cycles of $95^{\circ} \mathrm{C}$ for $45 \mathrm{~s}, 55^{\circ} \mathrm{C}$ for $1 \mathrm{~min}$, and $72^{\circ} \mathrm{C}$ for $2 \mathrm{~min}$; and $7 \mathrm{~min}$ of final elongation at $72{ }^{\circ} \mathrm{C}$.

Generation of gnotobiotic larvae. Methods described previously ${ }^{44}$ were used to generate germ-free and monoassociated larvae. In performing behavioral experiments to assess synergism, we noted that the response to skin extract is dependent on the concentration of substance as well as the sensitivity of the fish. We diluted thus the lysates and compared fish against siblings grown in the same conditions.

Uptake of fluorescently labeled bacteria and zymosan. Fish measuring $\sim 2 \mathrm{~cm}$ ( $\sim 6$ weeks old) were placed overnight in a beaker containing pHrodo Red labeled $E$. coli, S. aureus, or zymosan (Thermo Fisher P35361, A10010, P35364; $2 \mathrm{mg} / 50 \mathrm{~mL}$ E3). They were then transferred into clean water, labeled with SYTO 9 (1:5000), euthanized using MS222, and imaged using confocal microscopy. For long term imaging, fish were anesthesized and intubated as described ${ }^{70}$.

Mucus labeling. Fish were incubated in Alexa Fluor 594 WGA (1:1000 dilution of a $1 \mathrm{mg} / \mathrm{mL}$ stock; Thermo Fisher W11262) for $2 \mathrm{~h}$. To follow mucus uptake, fish were transferred into a tank with clean water for at least $15 \mathrm{~h}$

In situ hybridization. In situ hybridization was conducted with the EUB probe $\mathrm{e}^{71}$ (5'-GCT GCC TCC CGT AGG AGT-3') labeled with Alexa Fluor 546 (Nhydroxysuccinimide ester) at the $5^{\prime}$ end (IDT, USA). Four independent hybridizations were carried out. A second probe (5'-CGA CGG AGG GCA TCC TCA-3') gave similar results. To control for autofluorescence in imaging, samples were processed in parallel without any probe. Two-month-old fish that were less than 2 $\mathrm{cm}$ in length were fixed in $4 \%$ paraformaldehyde in phosphate buffered saline (PBS). Samples were washed once in methanol $(\mathrm{MeOH})$ for $10 \mathrm{~min}$ and then stored at $-20^{\circ} \mathrm{C}$ in $\mathrm{MeOH}$ for at least $2 \mathrm{~h}$. Prior to hybridization, fish were rehydrated to PBS with decreasing concentrations of $\mathrm{MeOH}(75,50$, and 25\%) in PBST (PBS with $0.1 \%$ Tween 20) for $5 \mathrm{~min}$ each. Samples were permeabilized in $10 \mu \mathrm{g} / \mathrm{mL}$ proteinase $\mathrm{K}$ for $5 \mathrm{~min}$, and subsequently fixed for $20 \mathrm{~min}$ in PFA. After washing in PBST, hybridization was carried out with $5 \mu \mathrm{g} / \mathrm{mL}$ of the probe in hybridization buffer ( $2 \times$ saline sodium citrate buffer, $50 \%$ formamide) and incubated at $37^{\circ} \mathrm{C}$ overnight. The samples were then washed in hybridization buffer once, followed by two washes $0.1 \times$ SSC and then two washes in PBS.

Following in situ hybridization, nuclei were labeled by incubation in 1:5000 dilution of SYTO 9 (Thermo Fisher) for $1 \mathrm{~h}$ at room temperature. Fish were then held securely on the cover of a petri dish, using $3 \%$ low melting temperature agarose in PBS, and imaged on a Zeiss LSM800 confocal microscope with a $\times 401.0$ N.A. water dipping objective. A pinhole of 1 Airy unit was used. Images form were median filtered (0.5) in Fiji, and contrast adjusted in Affinity Designer. Surface rendering was performed using Huygens Professional X11.

Quantitation of bacteria label. Z-stacks were maximally projected and the number of labeled cells was manually counted in FIJI.
Antibody label. Fish measuring $\sim 2 \mathrm{~cm}$ in length were euthanized by overdose in tricaine (Sigma A5040), and then fixed at room temperature in PBS containing 4\% paraformaldehyde. Following washing and permeabilization with PBS containing $0.1 \%$ Triton X-100, LC3B antibody (Abcam ab48934) was diluted 1:200 in PBS containing $0.1 \%$ Triton X-100 and $1 \%$ bovine serum albumin (Sigma A1470). For labeling $\beta$-catenin, the primary antibody (BD Bioscience 610153) was diluted 1:200, while cleaved Caspase-3 (Cell Signalling Technology 9661) and $\Delta$ Np63 (Santa Cruz SC-8341) were diluted 1:100. The secondary antibody, Alexa-568 goat anti-rabbit (Thermo Fisher A11011), or Alexa-647 goat anti-rabbit (Thermo Fisher A27040) was used at 1:1000. To label nuclei, fish were incubated in 1:5000 SYTO 9 (Thermo Fisher S35854) for $1 \mathrm{~h}$. Three independent labeling experiments were carried out for each antibody.

Actin label. Following fixation and rinsing, fish were permeabilized with $2 \%$ Triton $\mathrm{X}-100$ in PBS. Filamentous actin was labeled by overnight incubation in Alexa Fluor 568 phalloidin (Thermo Fisher A12380) at 1:20 dilution of a stock solution $(0.2$ units $/ \mu \mathrm{L})$ prepared in methanol.

Reporting Summary. Further information on research design is available in the Nature Research Reporting Summary linked to this article.

\section{Data availability}

Data on animal behavior and confocal imaging are available on Figshare [https://doi.org/ 10.6084/m9.figshare.8796695].

\section{Code Availability}

Software used to track fish and analyze their behavior is available on GitHub [https:// github.com/rkcheng/AlarmSubstance_AdultFish].

Received: 2 January 2019 Accepted: 22 July 2019

Published online: 23 August 2019

\section{References}

1. V. Frisch, K. Zur Psychologie des Fisch-Schwarmes. Naturwissenschaften 26, 601-606 (1938).

2. Pfeiffer, W. Alarm substances. Experientia 19, 113-123 (1963).

3. Schutz, F. Vergleichende Untersuchungen über die Schreckreaktion bei Fischen und deren Verbreitung. Z. Vgl. Physiol. 38, 84-135 (1956).

4. V. Frisch, K. Die Bedeutung des Geruchsinnes im Leben der Fische. Die Naturwissenschaften29, 321-333 (1941).

5. Pfeiffer, W. Schreckreaktion und Schreckstoffzellen bei Ostariophysi und Gonorhynchiformes. Z. Vgl. Physiol. 56, 380-396 (1967).

6. Pfeiffer, W. The distribution of fright reaction and alarm substance cells in fishes. Copeia 1977, 653 (1977)

7. Smith, R. J. F. Testosterone eliminates alarm substance in male fathead minnows. Can. J. Zool. 51, 875-876 (1973).

8. Hugie, D. M. \& Smith, R. J. F. Epidermal club cells are not linked with an alarm response in reedfish, Erpetoichthys (= Calamoichthys) calabaricus. Can. J. Zool. 65, 2057-2061 (1987).

9. Whitear, M. Epidermis. in Biology of the Integument (eds. Bereiter-Hahn, J., Matoltsy, A. G. \& Richards, K. S.) 29, 8-38 (Springer Berlin Heidelberg, Berlin 1986)

10. Chivers, D. P. et al. Epidermal 'alarm substance' cells of fishes maintained by non-alarm functions: possible defence against pathogens, parasites and UVB radiation. Proc. Biol. Sci. 274, 2611-2619 (2007).

11. Iger, Y., Abraham, M., Dotan, A., Fattal, B. \& Rahamim, E. Cellular responses in the skin of carp maintained in organically fertilized water. J. Fish Biol. 33, 711-720 (1988)

12. Iger, Y., Abraham, M. \& Wendelaar Bonga, S. E. Response of club cells in the skin of the carp Cyprinus carpio to exogenous stressors. Cell Tissue Res. 277, 485-491 (1994).

13. Halbgewachs, C. F., Marchant, T. A., Kusch, R. C. \& Chivers, D. P. Epidermal club cells and the innate immune system of minnows. Biol. J. Linn. Soc. Lond. 98, 891-897 (2009)

14. Mathuru, A. S. et al. Chondroitin fragments are odorants that trigger fear behavior in fish. Curr. Biol. 22, 538-544 (2012).

15. Sonal et al. Myosin $\mathrm{Vb}$ mediated plasma membrane homeostasis regulates peridermal cell size and maintains tissue homeostasis in the zebrafish epidermis. PLoS Genet. 10, e1004614 (2014).

16. Pinto, C. S. et al. Microridges are apical projections formed of branched Factin networks that organize the glycan layer. Preprint at bioRxiv https://www. biorxiv.org/content/10.1101/442871v1 (2018) 
17. Wirth, M., Gerhardt, K., Wurm, C. \& Gabor, F. Lectin-mediated drug delivery: influence of mucin on cytoadhesion of plant lectins in vitro. J. Control. Release 79, 183-191 (2002).

18. Winkel, J. G. J. V. D. et al. Glycosaminoglycans in the skin mucus of rainbow trout (Salmo gairdneri). Comp. Biochem. Physiol. Part B 85, 473-475 (1986).

19. Larsen, A. M. \& Arias, C. R. More than mucus: the hidden world of the fish microbiota. Fisheries 39, 154-154 (2014)

20. Shephard, K. L. Functions for fish mucus. Rev. Fish Biol. Fish. 4, 401-429 (1994).

21. Reverter, M., Tapissier-Bontemps, N., Lecchini, D., Banaigs, B. \& Sasal, P. Biological and ecological roles of external fish mucus: a review. Fishes 3, 41 (2018).

22. Dash, S., Das, S. K., Samal, J. \& Thatoi, H. N. Epidermal mucus, a major determinant in fish health: a review. Iran. J. Vet. Res. 19, 72-81 (2018).

23. Rasmussen, J. P., Vo, N.-T. \& Sagasti, A. Fish scales dictate the pattern of adult skin innervation and vascularization. Dev. Cell 46, 344-359.e4 (2018).

24. Ralphs, J. R. \& Benjamin, M. Chondroitin and keratan sulphate in the epidermal club cells of teleosts. J. Fish Biol. 40, 473-475 (1992).

25. Ray, P. H. \& Brock, T. D. Thermal lysis of bacterial membranes and its prevention by polyamines. J. Gen. Microbiol. 66, 133-135 (1971).

26. Eyngor, M. et al. Transcytosis of Streptococcus iniae through skin epithelia barriers: an in vitro study. FEMS Microbiol. Lett. 277, 238-248 (2007).

27. Iger, Y. \& Wendelaar Bonga, S. E. Cellular responses of the skin of carp (Cyprinus carpio) exposed to acidified water. Cell Tissue Res. 275, 481-492 (1994).

28. Chapman, G. B. \& Johnson, E. G. An electron microscope study of intrusions into alarm substance cells of the channel catfish. J. Fish Biol. 51, 503-514 (1997).

29. Lutfy, R. G. Studies on the epidermis of the catfish Synodontis schall. Ain Shams Sci. Bull. 10, 153-163 (1964).

30. Wang, X. Cell-in-cell phenomenon: a new paradigm in life sciences. Curr. Mol. Med. 15, 810-818 (2015).

31. Overholtzer, M. \& Brugge, J. S. The cell biology of cell-in-cell structures. Nat. Rev. Mol. Cell Biol. 9, 796-809 (2008).

32. Overholtzer, M. et al. A nonapoptotic cell death process, entosis, that occurs by cell-in-cell invasion. Cell 131, 966-979 (2007).

33. Humble, J. G., Jayne, W. H. \& Pulvertaft, R. J. Biological interaction between lymphocytes and other cells. Br. J. Haematol. 2, 283-294 (1956).

34. Garanina, A. S., Khashba, L. A. \& Onishchenko, G. E. Stages of cell cannibalism-entosis-in normal human keratinocyte culture. Biochemistry $\mathbf{8 0}$, 1469-1477 (2015).

35. Lee, R. T. H., Asharani, P. V. \& Carney, T. J. Basal keratinocytes contribute to all strata of the adult zebrafish epidermis. PLoS ONE 9, e84858 (2014).

36. Renshaw, S. A. et al. A transgenic zebrafish model of neutrophilic inflammation. Blood 108, 3976-3978 (2006).

37. Pluznick, J. L. et al. Olfactory receptor responding to gut microbiota-derived signals plays a role in renin secretion and blood pressure regulation. Proc. Natl Acad. Sci. USA 110, 4410-4415 (2013).

38. Triballeau, N. et al. High-potency olfactory receptor agonists discovered by virtual high-throughput screening: molecular probes for receptor structure and olfactory function. Neuron 60, 767-774 (2008).

39. Stensmyr, M. C. et al. A conserved dedicated olfactory circuit for detecting harmful microbes in Drosophila. Cell 151, 1345-1357 (2012).

40. Colucci-Guyon, E., Tinevez, J.-Y., Renshaw, S. A. \& Herbomel, P. Strategies of professional phagocytes in vivo: unlike macrophages, neutrophils engulf only surface-associated microbes. J. Cell Sci. 124, 3053-3059 (2011).

41. Amann, R. \& Fuchs, B. M. Single-cell identification in microbial communities by improved fluorescence in situ hybridization techniques. Nat. Rev. Microbiol. 6, 339-348 (2008).

42. Stephens, W. Z. et al. The composition of the zebrafish intestinal microbial community varies across development. ISME J. 10, 644-654 (2016).

43. Pandey, S., Shekhar, K., Regev, A. \& Schier, A. F. Comprehensive identification and spatial mapping of habenular neuronal types using singlecell RNA-seq. Curr. Biol. 28, 1052-1065.e7 (2018).

44. Melancon, E. et al. Best practices for germ-free derivation and gnotobiotic zebrafish husbandry. Methods Cell Biol. 138, 61-100 (2017).

45. Lebedeva, N. Y., Malyukina, G. A. \& Kasumyan, A. O. The natural repellent in the skin of cyprinids. J. Icthyol. 15, 472-480 (1975).

46. Shan, M. et al. Mucus enhances gut homeostasis and oral tolerance by delivering immunoregulatory signals. Science 342, 447-453 (2013).

47. Jerke, U. et al. $\beta 2$ integrin-mediated cell-cell contact transfers active myeloperoxidase from neutrophils to endothelial cells. J. Biol. Chem. 288 , 12910-12919 (2013).

48. Nadkarni, S. et al. Neutrophils induce proangiogenic T cells with a regulatory phenotype in pregnancy. Proc. Natl Acad. Sci. USA 113, E8415-E8424 (2016).

49. Rastogi, V., Sharma, R., Misra, S. R., Yadav, L. \& Sharma, V. Emperipolesis-a review. J. Clin. Diagn. Res. 8, ZM01-ZM02 (2014).
50. Xia, P., Wang, S., Guo, Z. \& Yao, X. Emperipolesis, entosis and beyond: dance with fate. Cell Res. 18, 705-707 (2008).

51. Ekman, D. R. et al. Metabolite profiling of fish skin mucus: a novel approach for minimally-invasive environmental exposure monitoring and surveillance. Environ. Sci. Technol. 49, 3091-3100 (2015).

52. Kotrschal, K. Solitary chemosensory cells: why do primary aquatic vertebrates need another taste system? Trends Ecol. Evol. 11, 110-114 (1996).

53. Williams, G. C. Natural Selection: Domains, Levels, and Challenges. (Oxford University Press, New York 1992).

54. Meuthen, D., Baldauf, S. A. \& Thünken, T. Evolution of alarm cues: a role for kin selection? F1000Research 1, 27 (2012).

55. Chivers, D. P. \& Brown, G. E. The evolution of chemical alarm signals: attracting predators benefits alarm signal senders. Am. Nat. 148, 649-659 (1996).

56. Mathis, A. \& Chivers, D. P. Chemical alarm signals: predator deterrents or predator attractants? Am. Nat. 145, 994-1005 (1995).

57. Chivers, D. P., Brown, G. E. \& Ferrari, M. C. O. The evolution of alarm substances and disturbance cues in aquatic animals, in Chemical Ecology in Aquatic Systems (eds. Brönmark, C. and Hansson, L.-A.) 127-139 (Oxford University Press Inc., New York 2012).

58. Cashner, M. F. Are spotted bass (Micropterus punctulatus) attracted to schreckstoff? A test of the predator attraction hypothesis. Copeia 2004, 592-598 (2004).

59. Carreau-Green, N. D., Mirza, R. S., MartÍnez, M. L. \& Pyle, G. G. The ontogeny of chemically mediated antipredator responses of fathead minnows Pimephales promelas. J. Fish. Biol. 73, 2390-2401 (2008)

60. Theis, K. R. et al. Symbiotic bacteria appear to mediate hyena social odors. Proc. Natl Acad. Sci. USA 110, 19832-19837 (2013).

61. Hong, E. et al. Cholinergic left-right asymmetry in the habenulointerpeduncular pathway. Proc. Natl Acad. Sci. USA 110, 21171-21176 (2013).

62. DeMaria, S. et al. Role of a ubiquitously expressed receptor in the vertebrate olfactory system. J. Neurosci. 33, 15235-15247 (2013).

63. Koide, T. et al. Olfactory neural circuitry for attraction to amino acids revealed by transposon-mediated gene trap approach in zebrafish. Proc. Natl Acad. Sci. USA 106, 9884-9889 (2009).

64. Dauga, C. Evolution of the gyrB gene and the molecular phylogeny of enterobacteriaceae: a model molecule for molecular systematic studies. Int. J. Syst. Evol. Microbiol. 52, 531-547 (2002).

65. Adékambi, T., Drancourt, M. \& Raoult, D. The rpoB gene as a tool for clinical microbiologists. Trends Microbiol. 17, 37-45 (2009).

66. Schindelin, J. et al. Fiji: an open-source platform for biological-image analysis. Nat. Methods 9, 676-682 (2012)

67. Carlson, J. M., Leonard, A. B., Hyde, E. R., Petrosino, J. F. \& Primm, T. P. Microbiome disruption and recovery in the fish following exposure to broadspectrum antibiotic. Infect. Drug Resist. 10, 143-154 (2017).

68. Vingataramin, L. \& Frost, E. H. A single protocol for extraction of gDNA from bacteria and yeast. Biotechniques 58, 120-125 (2015).

69. Cardinale, M. et al. Comparison of different primer sets for use in automated ribosomal intergenic spacer analysis of complex bacterial communities. Appl. Environ. Microbiol. 70, 6147-6156 (2004).

70. Xu, C., Volkery, S. \& Siekmann, A. F. Intubation-based anesthesia for longterm time-lapse imaging of adult zebrafish. Nat. Protoc. 10, 2064-2073 (2015).

71. Amann, R. I. et al. Combination of $16 \mathrm{~S}$ rRNA-targeted oligonucleotide probes with flow cytometry for analyzing mixed microbial populations. Appl. Environ. Microbiol. 56, 1919-1925 (1990).

72. Ho, J., Tumkaya, T., Aryal, S., Choi, H. \& Claridge-Chang, A. Moving beyond P values: data analysis with estimation graphics. Nat. Methods 16, 565-566 (2019).

\section{Acknowledgements}

We thank Ajay Mathuru for help in optimizing the set-up for monitoring behavior and Sven Pettersson for discussion. This research is supported by the Lee Kong Chian School of Medicine, Nanyang Technological University Singapore Start-Up Grant (to S.J.), the Ministry of Education Singapore under award MOE2017-T2-058 (to S.J.), and by the National Institute of General Medical Sciences of the National Institutes of Health under award numbers P50GM098911 (to K.G.) and P01GM125576 (to K.G.). The content is solely the responsibility of the authors and does not necessarily represent the official views of the National Institutes of Health

\section{Author contributions}

J.S.M.C. performed behavior assays and analysis, ARISA and in situ hybridization. E.S.W prepared lysates from germ-free and monoassociated larval zebrafish. C.W. devised the method for preparing effective lysates from larval zebrafish, prepared conventional and germ-free lysates, and analyzed behavior data. T.A.J.R. characterized cell internalization. R.K.C. wrote the software for the behavior assay and analyzed behavior data. K.C. performed qPCR to quantitate bacterial load and generated the $T g(n b t: j G C a M P 7 f) s q 214$ line. K.G. designed experiments on using germ-free fish. S.J. conceived the project and designed experiments, performed calcium imaging, pulse chase of epithelial cells, tracing of bacteria, and wrote the manuscript. All authors edited and approved the manuscript. 


\section{Additional information}

Supplementary Information accompanies this paper at https://doi.org/10.1038/s41467019-11608-9.

Competing interests: The authors declare no competing interests.

Reprints and permission information is available online at http://npg.nature.com/ reprintsandpermissions/

Peer review information: Nature Communications thanks Thomas Bosch, Douglas Chivers and other anonymous reviewer(s) for their contribution to the peer review of this work. Peer reviewer reports are available.

Publisher's note: Springer Nature remains neutral with regard to jurisdictional claims in published maps and institutional affiliations. (c) (i) Open Access This article is licensed under a Creative Commons Attribution 4.0 International License, which permits use, sharing, adaptation, distribution and reproduction in any medium or format, as long as you give appropriate credit to the original author(s) and the source, provide a link to the Creative Commons license, and indicate if changes were made. The images or other third party material in this article are included in the article's Creative Commons license, unless indicated otherwise in a credit line to the material. If material is not included in the article's Creative Commons license and your intended use is not permitted by statutory regulation or exceeds the permitted use, you will need to obtain permission directly from the copyright holder. To view a copy of this license, visit http://creativecommons.org/ licenses/by/4.0/.

(C) The Author(s) 2019 